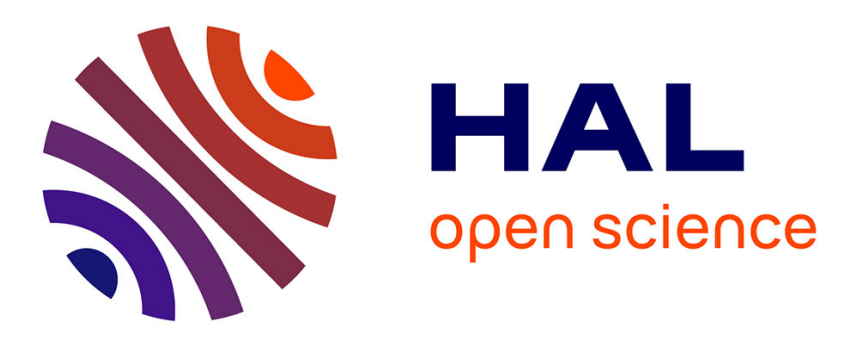

\title{
Reproductive ecology of Saxifraga florulenta, a monocarpic perennial paleo-endemic of the Alps
}

Maria Guerrina, Gabriele Casazza, Davide Dagnino, Macrì Carmelo, Roccotiello Enrica, Luigi Minuto

\section{- To cite this version:}

Maria Guerrina, Gabriele Casazza, Davide Dagnino, Macrì Carmelo, Roccotiello Enrica, et al.. Reproductive ecology of Saxifraga florulenta, a monocarpic perennial paleo-endemic of the Alps. Plant Biosystems, 2022, 156 (1), pp.252-260. 10.1080/11263504.2020.1852328 . hal-03019146

\section{HAL Id: hal-03019146 \\ https://hal-amu.archives-ouvertes.fr/hal-03019146}

Submitted on 23 Nov 2020

HAL is a multi-disciplinary open access archive for the deposit and dissemination of scientific research documents, whether they are published or not. The documents may come from teaching and research institutions in France or abroad, or from public or private research centers.
L'archive ouverte pluridisciplinaire HAL, est destinée au dépôt et à la diffusion de documents scientifiques de niveau recherche, publiés ou non, émanant des établissements d'enseignement et de recherche français ou étrangers, des laboratoires publics ou privés. 


\title{
Reproductive ecology of Saxifraga florulenta, a monocarpic perennial paleo-endemic of the Alps
}

\author{
Maria Guerrina ${ }^{1}$, Gabriele Casazza ${ }^{1,2}$, Davide Dagnino ${ }^{1}$, Macrì Carmelo ${ }^{1}$, Roccotiello Enrica ${ }^{1}$, Luigi \\ Minuto ${ }^{1}$. \\ ${ }^{1}$ Università di Genova, Dipartimento di Scienze della terra, Ambiente e Vita, Corso Europa 26, I- \\ 16132 Genova, Italy.
}

${ }^{2}$ Aix Marseille Université, Avignon Université, Institut méditerranéen de biodiversité et d'écologie marine et continentale (IMBE), CNRS, IRD. Technopôle de l'Arbois-Méditerranée, BP 80, F-13545 Aix-en-Provence cedex 4, France

Corresponding author: Luigi Minuto, e-mail: luigi.minuto@unige.it phone number: +39 0103359361

\begin{abstract}
Saxifraga florulenta is a monocarpic species endemic to SW Alps, whose reproductive biology is still unknown. Its knowledge may provide useful information on how the species may face the global warming. In this study, we investigated the plant-pollinator interactions and the mating system of the plant. We described the phenology of the inflorescences, we evaluated the type of pollinators, we verified self and cross-pollination and lastly we quantified the reproductive success of the plants. In spite of the low visitation rate of pollinators, S. florulenta shows high fruit set and seed set. The plant exhibits a prolonged flowering period and has a definite inflorescence, characterized by a sequential blooming bearing both female- or male-phase flowers at the same time; in addition, flowers show a delayed maturation and movement of stamens. These floral and inflorescence traits lead to a mixed reproduction mode which guarantees reproductive success by adopting the "best of two worlds" strategy. The species maximizes its resource investment by having inflorescence size and number of flowers directly related to plant size, whilst fruit and seed set as well as seeds per flower did not show any statistically significant relationship with plant size.
\end{abstract}

Keywords Saxifraga florulenta Moretti - Saxifragaceae - paleo-endemic plant species - pollen vectors -reproductive strategy - resource investment.

\section{Introduction}

Alpine habitats are stressful environments, characterized by harsh climatic conditions because of low temperature, short vegetation period, snowfall and weather-related extreme events (Gugerli 1998). Under such harsh and stochastic climatic conditions, pollinators are scarce (Muñoz and Arroyo 2006) resulting in in a reduction of flower visitation rate, pollen loads and opportunities for crosspollination (Brys et al. 2011; Knight et al. 2005; Medan et al. 2002), which lead to a low fruit and seed production (e.g., Aizen and Feinsinger 1994; Cunningham 2000). However, entomophily is a common strategy in alpine habitats (Arroyo et al. 1982; Körner 1999; Medan et al. 2002) and even low pollinator visitation rates are critical for reproductive success in these habitats (Muñoz and Arroyo 2006). When species face recurrent or chronic pollination limitation, two main hypotheses can explain their persistence: "reproductive assurance" (Stebbins 1950; Lloyd 1992; Lloyd and Schoen 1992) and "increased pollination probability" (Billings and Mooney 1968; Bliss 1971). According to the former hypothesis, weak reliance on pollinators leads to autonomous selfing to ensure fast pollination in the short time available for seed development (Gugerli 1998). In alpine plants, transition towards self-fertilization has been suggested as an evolutionary solution to cope with low pollinator availability (Torres-Díaz et al. 2011). According to the latter hypothesis, an 
increase in flower attractiveness (larger flowers or inflorescences), in flower longevity, and in stigma receptivity compensate for the scarcity of pollinators (Arroyo et al. 1985; Bingham and Orthner 1998; Fabbro and Korner 2004). The stronger interactions with pollinators favour cross-pollination in order to maintain high genetic diversity, fundamental for population persistence in highly stochastic environments such as alpine habitats (Fabbro and Körner 2004).

In any case, the strategies described above are affected by the available resources. Individual plant size is usually considered one of the best predictors of reproductive output (Stearns 1992). At plant level, the reproductive output is expected to increase with size as a consequence of a greater availability of resources for large plants (De Jong and Klinkhamer 1989; Sletvold 2002). In fact, large plants may increase both female and male reproductive output because they attract more pollinators, and this could result in higher levels of both pollen deposition and removal. On the contrary, in small plants seeds development may be curtailed more severely than in large ones (De Jong and Klinkhamer 1994). Moreover, in species having an inflorescence, the use of resources may also vary at the flower level. In sequentially blooming inflorescences, the relative allocation of resources to pollen versus ovule production varies among flowers (Brunet and Charlesworth 1995; Mazer and Dawson 2001): ovule production is expected to decline from basal (early-opening) to distal (late-opening) flowers (Brunet and Charlesworth 1995; Mazer and Dawson 2001; Gao et al. 2015), while pollen production changes slightly or remains constant (Diggle 1997; Mazer and Dawson 2001; Guitián et al. 2004; Delesalle et al. 2008; Ishii and Harder 2012).

To investigate further all these aspects, the alpine monocarpic perennial plants are a suitable case study. In fact, since alpine monocarpic plants invest all of their available resources in a single reproductive event, they have to ensure their reproductive success under harsh climatic conditions resulting in low pollination service and short season (Kudo 1991; Molau 1996; Ashman et al. 2004) without any trade-off between current reproduction and future demographic costs (Cao et al. 2008). An improved understanding of their reproductive biology may provide useful information on resources investment and sex allocation during their only reproductive event, and how they might survive in the framework of climate change (Munne-Bosch et al. 2016). The genus Saxifraga includes many species growing under harsh climatic conditions (Molau and Prentince 1992; Gugerli 1998; Brochmann and Hapnes 2001). They adopt a wide array of reproductive strategies with regard to mating system and pollen vectors (Lindgaard-Hansen and Molau 1994). However, monocarpy is relatively rare in Saxifraga (6 out of 450-500 species - Conti et al. 1999; Dinnétz and Nilsson 2002) and it has likely arisen several times independently (Conti et al. 1999; Zhang 2013; Deng et al. 2015; Tkach et al. 2015). In addition, six monocarpic species grow in mountain environment, four out of six in Europe (S. mutata L., S. cotyledon L., S. longifolia Lapeyr., and S. florulenta Moretti; Webb and Gornall 1989) and two out of six in the mountains of China (S. umbellulata and S. candelabrum; Conti et al. 1999). Among the European saxifrages, the reproductive ecology has been studied in two of these species [i.e., S. mutata (Holderegger 1996) and S. longifolia (Garcia 2003)], while it is still unknown for S. cotyledon and S. florulenta.

The purpose of this study was to investigate the reproductive ecology in S. florulenta. The specific goals of this study were: a) to describe the phenology of flowers and inflorescence; b) to evaluate the type and the frequency of pollinators; c) to define the reproduction mode of the species; d) to quantify its resources investment, sex allocation, and reproductive success.

\section{Material and methods}

\section{Plant species and study sites}

Saxifraga florulenta Moretti (Saxifragaceae) is endemic to the Argentera-Mercantour massif in the Maritime Alps and it has a very narrow distributional range (about 100 square kilometres; Szövény et al. 2009; Patsiou et al. 2014). It grows exclusively on high-altitude siliceous cliffs, above 2,000 m 
a.s.l. The number of populations is low (approximately 100; Focquet and Romain 1988; Szövény et al. 2009; Juillet and Zappa 2011), as well as the number of individuals per population (ranging from less than 10 to 300; Szövény et al. 2009). The species blooms during summer after a long vegetative period (variable from 15 to 25 years, but the precise time is still undefined) and the number of specimens blooming simultaneously strongly varies among years, with an extraordinarily large number of flowering plants in some years. The duration of the vegetative period and the occurrence of flowering events seem to be linked to cold winters (Focquet and Romain 1988).

Saxifraga florulenta has been suggested to be an element of the palaeoflora based on its low morphological variation and distinctive life history (long-lived, monocarpic - Martini 1982; GreyWilson 1985), its narrow ecological requirement (Patsiou et al. 2014) and its isolated phylogenetic position in the genus (Tkach et al. 2015). Its diversification has been estimated at Late Miocene or Pliocene (Ebersbach et al. 2017).

This study was performed during two abundant flowering seasons in 2011 and 2014, when many flowering specimens were detected. During both years, from June to September, two populations were monitored: one in the Gesso Valley (Piedmont - Italy) at Lago del Chiotas, in the Vallone della

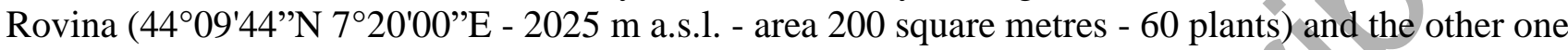

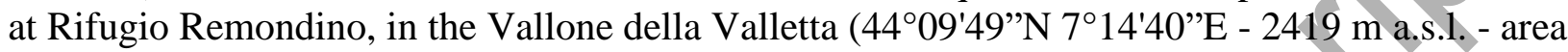
500 square metres - 150 plants).

\section{Floral and inflorescence phenology}

In 2011 and 2014, floral phenology and inflorescence development were observed in the field on 15 randomly selected individuals in the two populations (see Table 1). For each inflorescence, the following parameters were recorded: basal rosette diameter, inflorescence stem height, number of flowers, and number of different flowers per order (primary, secondary and tertiary flowers).

The onset and duration of stigma receptivity were visually evaluated on five flowers for each of five selected inflorescences during anthesis (20 days). According to literature, in many high mountain Saxifraga species stigmas receptivity lasts as long as stigmas look fresh (red colour), and it ends when they wither (brown colour) (Steinacher and Wagner 2010).

\section{Pollination}

In 2011, pollinator visits and activity on S. florulenta were documented at the peak of the flowering season (from July to August) at Rifugio Remondino. Insect visitation was monitored on 10 inflorescences (all plants grew within a distance of $20 \mathrm{~m}$ ) during periods of 30 min from 9 a.m. to 7 p.m. over 30 sunny days. Insects were identified directly in the field or collected for later laboratory identification. Pollinator visitation rate per inflorescence was calculated according to Torres-Díaz et al. (2011).

\section{Reproduction mode}

In 2014, pollinator visits were prevented by bagging 30 randomly chosen flower buds from eight different inflorescences in both populations with non-woven fabric in order to detect the occurrence of autonomous self-fertilization. To verify the occurrence of cross-pollination, 30 randomly chosen flower buds on different inflorescences at Rifugio Remondino were marked and manually emasculated to prevent self-pollination. After 15 weeks, the emasculated and bagged flowers were harvested, and fruit set and seed set were calculated. The fruit set and seed set from the reproductive success test (see below) were used as control for open-pollination. 
To analyse the correlation between plant size (basal rosette diameter, floral stem height) and male and female investment (flower and seed production, respectively) data from the 15 individuals previously employed in the assessment of floral and inflorescence phenology were used. Flower number (estimator of pollen production) and the average number of seeds per flower were used as paternal and maternal investment proxy respectively, following the approach of Garcia (2003).

In order to assess the potential displacement of resources along the inflorescence, each floral stem was subdivided into three sections equal in length: basal, median and apical. Due to its different morphological features (see Results), the uppermost flower (terminal) was considered separately.

To investigate the sex allocation of the plant and the degree of maleness and femaleness in the inflorescences, the pollen:ovule ratio (P:O) was calculated on a total of 24 flowers sampled in the three sections. To estimate the number of pollen grains per flower, $500 \mu 1$ of $70 \%$ ethanol and $50 \mu 1$ of basic fuchsine (1\% in water) were added to all anthers of each flower and vortexed for ten minutes. Grains were counted in three replicates per flower, using a Fuchs-Rosenthal cell counter under an optical microscope (Leica DM2000). To count the number of ovules per gynoecium, flowers were manually dissected and observed under a Leica M205 C stereomicroscope.

To verify the reproductive success of the species, fruit set (fruits/flowers) and seed set (seeds/ovules) were calculated on the same 15 individuals previously mentioned for the study on floral and inflorescence phenology. Before seed dispersal (boleochory - Vittoz and Engler 2007), inflorescences were harvested and the numbers of fruits were counted. Only primary flowers were taken into account, because secondary and tertiary ones did not reach a complete fruit ripeness before the beginning of dispersal. For each inflorescence two fruits per section plus the terminal one (when present) were manually dissected $(n=100)$ and seeds and ovules (seeds + aborted ovules) were counted under a Leica M205 C stereomicroscope.

\section{Statistical analysis}

The non-parametric Kruskal-Wallis test and Nemenyi-Damico-Wolfe-Dunn post hoc test were used to detect pairwise differences in productivity both between inflorescence sections and treatments (emasculated, bagged and open-pollinated flowers) and among P:O ratios implemented in the package PMCMR (Pohlert 2014) in R (R Development Core Team, 2008). Kendall Tau correlation coefficients were calculated to assess the correlation between plant size, and male and female investment using the R package Hmisc (Harrell 2017).

\section{Results}

\section{Floral and inflorescence phenology}

Flowering individuals showed a diameter of the basal rosette ranging from 5.5 to $18 \mathrm{~cm}$ (mean 10.37 SD 3.93; Table 1). The inflorescences were variably branched panicles having a height from 12 up to $44 \mathrm{~cm}$ (mean 26.50 SD 11.52; Table 1), 2.5 times the dimension of the basal rosette (mean $2.52 \mathrm{SD}$ 0.39; Table 1). Branches only occurred in large panicles and could be up to $7.5 \mathrm{~cm}$ (mean $3.02 \mathrm{SD}$ 2.06) long, bearing up to three flower orders. Panicles bore from 51 up to 228 flowers (mean 134.07 SD 63.34; Table 1 and Appendix 1). All flowers had five white petals, five pink sepals and ten anthers. The terminal one had supernumerary organs showing up to twice the number of all parts.

The first blooming flower was the terminal one (Fig. 1). Then, at least a week after, the other flowers opened sequentially from the bottom to the top. In large inflorescences, three orders of flowers bloomed sequentially from the bottom to the top of the inflorescence producing acropetally blooming waves. Within each branch, in fact, the first flower to bloom was the one at the tip (first order, $n=50-133$; Table 1). After 10-15 days, when the first order blooming sequence was about to 
reach the upper part of the inflorescence, the second flower of the branches at the bottom started to open (second order, $\mathrm{n}=1-84$; Table 1), generating a second blooming wave. In largest inflorescences, a third set of flowers (third order, $n=1-17$; Table 1) may bloom. The blooming period of a plant lasted about two months and each flower had a duration of 15-20 days.

Flowers were all protandrous and each inflorescence simultaneously bore developing fruits, male- or female-phase flowers, and flower buds. In each flower, the male phase lasted several days due to the asynchronous maturation of stamens, with half of the anthers dehiscent while the stigma was not yet receptive (Fig. 2a). Just before flower senescence, the other half of the stamens collapsed towards the centre of the flower pushing their dehiscent anthers on the still receptive stigma (Fig. $2 b)$. The onset of stigma receptivity started after about five days from the beginning of anthesis and lasted up to 15 days, resulting in incomplete protandry (sensu Lloyd and Webb 1986).

\section{Pollen vectors}

A total of 13 insect species were observed on S. florulenta inflorescences (Table 2). An overall of 28 visits were carried out by Diptera (40.68\%), followed by Hymenoptera (25.42\%) and Coleoptera $(11.86 \%)$, while other phytophagous insects (Lepidoptera $=11.86 \%$, Thysanoptera $=10.17 \%$ ) were observed both in larval and adult stages on some floral parts [e.g., Kessleria saxifragae (Stainton, 1868) - Yponomeutidae]. Pollinator visitation rate was very low, with an average of 0.043 visits per inflorescence per $30 \mathrm{~min}$. Insect visits were most frequent at the warmest hours of the day (from 12 pm to $2 \mathrm{pm})$.

\section{Reproduction mode}

Open-pollinated flowers showed a mean fruit set of 0.98 SD 0.03 (Table 3 and Appendix 1) and a mean seed set of 0.76 SD 0.10 (Table 4 and Appendix 2). Bagged flowers showed a mean fruit set of 0.90 SD 0.31 (Appendix 3) and a mean seed set of 0.71 SD 0.15 (Appendix 3), while emasculated flowers showed a mean fruit set of 1.00 SD 0.00 (Appendix 3) and a mean seed set of 0.54 SD 0.23 (Appendix 3), significantly lower than in the other treatments (Figure 3).

\section{Resources investment, sex allocation and reproductive success}

Plant size (i.e., rosette diameter and inflorescence height) was positively correlated with the male and female investment, which is the number of flowers per stem and the average number of seeds per flower, respectively (Table 5).

The mean pollen production was 16,408.61 (SD 6345.47) grains per anther, with constant but nonsignificant increment from basal to apical flowers along the inflorescence (Table 6). In particular, the high production of the terminal flower (mean production $=22,791.67 \mathrm{SD} 11,136.93$ ) was due to its supernumerary nature (Table 6). The mean ovule production was 470.40 (SD 154.75), with constant and significant decrement from basal to apical flowers along the inflorescence (Table 6). The mean P:O ratio of flowers was 39.87 SD 18.75 (Table 6), but it varied in differently positioned flowers and showed an increasing male-phase along the sections (Table 6). The P:O ratio incremented from basal to apical flowers $(p=5.3 \mathrm{e}-13$ and $\mathrm{p}=9.0 \mathrm{e}-12$, respectively) with an increasing male functionality at the end of the blooming period.

The reproductive success was high, i.e., fruit set $=0.98$ SD 0.03 and seed set $=0.76$ SD 0.10 , respectively (Tables 3 and 4). The probability of setting fruit and seed did not differ significantly among sections of the inflorescence (Tables 3 and 4).

\section{Discussion}


In the inflorescence of $S$. florulenta, the terminal flower blooms first and stops the apical meristem; subsequently, first flower order bloom in sequence from the base towards the apex of the inflorescence. Second and third order flowers continuously decrease in number towards the apex and they show a centripetal flowering sequence on each branch. These results suggest that $S$. florulenta has a closed inflorescence (botryoid when it bears only first order flowers, or thyrse when second and third order flowers are present) with acropetal flowering sequences (Bull-Hereñu and ClaßenBockhoff 2011; Claßen-Bockhoff and Bull-Hereñu 2013). This acropetal sequential blooming has been previously reported in other monocarpic Saxifraga species like S. longifolia (Garcia 2003), S. mutata (Holderegger 1996) and S. cotyledon (Dinnétz and Nilsson 2002). However, differently from the other monocarpic Saxifraga species, S. florulenta exhibits a closed inflorescence, a character interpreted in the past as an ancestral trait (Bull-Hereñu and Claßen-Bockhoff 2011), which would further supports the old age of this species compared to its closest relatives and other monocarpic saxifrages (Conti et al. 1999; Conti and Rutschmann 2004; Soltis et al. 2013; Tkach et al. 2015; Ebersbach et al. 2017).

Some flower traits (i.e. asynchronous anther maturation, stamen movement and flowering duration) primarily favour cross-pollination, allowing later self-pollination. These features are detected in other co-generic species like S. mutata (Holderegger 1996), S. longifolia (Garcia 2003), S. hirculus L. (Ohlson 1988), S. oppositifolia L. (Gugerli 1998) and others (Brochmann and Hapnes 2001).

In S. florulenta, $78 \%$ of observed insects are common plant pollinators (i.e. Diptera, Hymenoptera and Coleoptera), suggesting a generalist pollination system characterized by both apterous and winged insects. The most frequent visitors are dipterans (roughly $40.68 \%$ ) as previously observed in S. longifolia, a co-generic and monocarpic plant living in the Western Mediterranean (Garcia 2003). Dipterans are common pollinators in the genus Saxifraga (i.e. S. hirculus - Olesen and Warncke 1989; S. granulata L. - Lindgaard-Hansen and Molau 1994; S. mutata - Holderegger 1996; S. longifolia - Garcia 2003) and in species growing at high altitude, like S. florulenta, where true flies are dominant (Arroyo et al. 1982; Elberling and Olesen 1999; Olesen and Jordano 2002). Even if true flies are generally considered inefficient pollinators compared to bees (Narbona and Dirzo 2010), they are known to play a key role in the reproduction of alpine species (Brown and McNeil 2009; Fulkerson et al. 2012).

The disc-shaped actinomorphic flowers, typical of the genus Saxifraga, attract many different kinds of insects (Lindgaard-Hansen and Molau 1994). This may be an advantage both for species with high visitation frequency (e.g. 2.2 visits per bout observed in Danish populations of S. hirculus restricted to spring areas rich in electrolytes - Olesen and Warnacke 1989) and for those with low visitation frequency growing in a harsh climatic condition such as $S$. florulenta. Moreover, in S. florulenta some floral and inflorescence features may favour both cross and geitonogamous pollination. In fact, the simultaneous occurrence of male- or female-phase flowers due to the sequential blooming, the blooming waves and the observed floral features (i.e., incomplete flower protandry, asynchronous stamen dehiscence, and long stigma receptivity) may allow insects to visit flowers at different maturation stages along the same or different inflorescences. However, the mean visitation rate observed in S. florulenta is very low compared to those reported for S. longifolia (0.72-0.78 - Garcia 2003), but is similar to that observed in other species endemic to the same geographic area (0.075, Berardia subacaulis Vill., Asteraceae - Guerrina et al. 2016) and in other species living at highaltitude (0.051, Campanula rotundifolia L., Campanulaceae - Bingham and Orthner 1998). The low visitation rate recorded in $S$. florulenta is congruent with the significantly lower seed set (roughly $50 \%$ ) detected in the emasculated flowers compare to bagged and open-pollinated treatments (Fig. 3 ). Our results suggest that, together with cross-pollination, autogamy plays an important role in the reproductive biology of the species, as confirmed by the P:O ratio values, typical of an autogamous species (Cruden 1977). 
Bagging and emasculation experiments showed that in both cases flowers produced seeds (Fig. 3). These results demonstrated that $S$. florulenta is characterized by a mixed mating system based on both crossing and selfing strategies, as observed in many other Saxifraga species growing in harsh climatic conditions (Molau and Prentice 1992; Gugerli 1998; Brochmann and Hapnes 2001). While incomplete protandry (sensu Lloyd and Web 1986) promotes outcrossing, self-compatibility may ensure reproductive success in alpine habitats where pollinator service and opportunities for crosspollination are reduced (Brys et al. 2011; Knight et al. 2005; Medan et al. 2002).

For a monocarpic species living at high altitudes like $S$. florulenta, a mixed mating system may ensure a constant high reproductive success (Table 3 and 4). As observed in S. mutata (Holderegger 1996), a combined reproductive system ensures high fruit set and seed set in open pollinated flowers, while the contrary has been observed in the almost obligate out-crossing species S. oppositifolia (Stenström and Molau 1992). In general, in S. florulenta fruit set and seed set were constantly high (Tables 3, 4), independent of plant size (Table 5). This is expected for a monocarpic species, which, having only one opportunity for its reproduction, shall invest all its available resources for a high reproductive success (Young and Augspurger 1991). The lack of any correlation between seed set and plant size has been detected also in other monocarpic perennial species, like S. longifolia (Garcia 2003) and Cardiocrinum cordatum (Thunb.) Makino (Liliaceae - Cao and Kudo 2008). These results are in contrast with what has usually been observed for monocarpic hermaphrodite plants, where size-dependent changes in seed production might be common when resources for reproduction are limited (De Jong and Klinkhamer 1989). However, it should be considered that in animal-pollinated species seed development may be curtailed more severely in small than in large plants (De Jong and Klinkhamer 1994). Similarly, a size-related allocation pattern is not expected when seed production is not limited by pollination (Klinkhamer and De Jong 1997) as in S. florulenta, an autogamous species characterized by a mixed mating system.

At floral level, we observed variation in sex allocation among flowers at different positions. More specifically, the early blooming flowers produced significantly more ovules than the late blooming ones and, consequently, the P:O ratio increased from the early to the late blooming flowers (Table 6). Our results are in line with the expectation for sequentially blooming plants (Brunet and Charlesworth 1995) that may adopt variations in sex allocation if the probability of successful pollen donation and receipt of individual flowers varies among individual flowers. For instance, if pollen grains from differently positioned flowers have different opportunities for siring offspring, the fitness contribution through male functions can vary among flowers (Ishii and Sakai 2002). In S. florulenta such variation is produced by the incomplete protandry, thus early-opening flowers allocate more resources to the female function because, when these flowers are in the female stage, more pollen will be available (Brunet and Charlesworth 1995).

\section{Conclusions}

Our study suggests that both the "reproductive assurance" (i.e., sexual reproduction relies on selffertilization) and the "increased pollination probability" (i.e., sexual reproduction relies on crossferitlization) hypotheses can explain the persistence of $S$. florulenta. In fact, our study shows that $S$. florulenta is characterized by a mixed mating system based on both crossing and selfing strategies. The reproductive mode of $S$. florulenta, with the possibility of delayed self-pollination, adopts "thebest-of-both-worlds" strategy allowing plants to cope both with variable pollinator environments (Goodwillie and Weber 2018) and with the variability in the number of flowering individuals in populations (Guerrina et al., 2013). This is in line with the expectation for a monocarpic species, which, having only one possibility for its reproduction, shall implement all its available resources for a high reproductive success (Young and Augspurger 1991). At the same time, it might explain the survival of $S$. florulenta endemic to a small glacial refugium, at high altitude and with a strong substrate specificity (Szövényi et al. 2009). In the face of climate change, which is expected to cause a decline in pollinators for mountain plants (Thomann et al. 2013), S. florulenta seems not to be 
exposed to such a risk, which is detrimental to the reproductive success of obligate outcrossers. Even if an increased self-pollination system might allow the species to survive in a changing environment, it might lead to a substantial reduction of genetic diversity, which might negatively affect the adaptive potential of the species (Levin 2012).

\section{Acknowledgments}

We are grateful to L. Galli (DISTAV, University of Genoa) for insect identification. Special thanks to Tommaso Ruberto, Elio Guerra, Alex Riggi and Simona Buchicchio for performing field investigations during their Bachelor and Master traineeship. This work was supported by a grant from Parco Naturale delle Alpi Marittime and Interreg Alcotra BIODIVAM project J72D13000070007 within ALCOTRA European Programme. GC gratefully acknowledges financial support from the European Union's Horizon 2020 Research and Innovation Programme [Grant Agreement No. 793226].

\section{References}

Aizen MA, Feinsinger P. 1994. Forest fragmentation, pollination, and plant reproduction in a Chaco dry forest, Argentina. Ecology. 175: 330-351. doi: 10.2307/1939538

Arroyo MTK, Primack RB, Armesto JJ. 1982. Community studies in pollination ecology in the high temperate Andes of central Chile. I. Pollination mechanisms and altitudinal variation. Am J Bot. 69: 82-97. doi: 10.1002/j.1537-2197.1982.tb13237.x

Arroyo MTK, Primack RB, Armesto JJ. 1985. Community studies in pollination ecology in the high temperate Andes of central Chile II. Effect of temperature on visitation rates and pollination possibilities. Plant Syst Evol. 149: 187-203. doi: 10.1007/BF00983305

Ashman TL, Knight TM, Steets JA, Amarasekare P, Burd M, Campbell DR, Dudash MR, Johnston MO, Mazer SJ, Mitchell RJ, Morgan MT, Wilson WG. 2004. Pollen limitation of plant reproduction: ecological and evolutionary causes and consequences. Ecology. 85: 2408-2421. doi: $0.1890 / 03-8024$

Billings WD, Mooney HA. 1968. The ecology of arctic and alpine plants. Biol Rev. 43: 481-529. doi: 10.1111/j.1469-185X.1968.tb00968.x

Bingham RA, Orthner AR. 1998. Efficient pollination of alpine plants. Nature. 391: 238-239.

Bliss LC. 1971. Arctic and alpine plant life cycles. Annu Rev Ecol Evol S. 2: 405-438. doi: 10.1146/annurev.es.02.110171.002201

Brochmann C, Hapnes A. 2001. Reproductive strategies in some arctic Saxifraga (Saxifragaceae), with emphasis on the narrow endemic $S$. svalbardensis and its parental species. Bot J Linn Soc. 137: 31-49. doi: 10.1111/j.1095-8339.2001.tb01103.x

Brown AO, McNeil JN. 2009. Pollination ecology of the high latitude, dioecious cloudberry (Rubus chamaemorus; Rosaceae). Am J Bot. 96: 1096-1107. doi: 10.3732/ajb.0800102

Brunet J, Charlesworth D. 1995. Floral sex allocation in sequentially blooming plants. Evolution. 49: 70-79. doi: 10.1111/j.1558-5646.1995.tb05959.x 
Brys R, De Crop E, Hoffmann M, Jacquemyn H. 2011. Importance of autonomous selfing is inversely related to population size and pollinator availability in a monocarpic plant. Am J Bot. 98: 1834-1840. doi: 10.3732/ajb.1100154

Bull-Hereñu K., Claßen-Bockhoff R. 2011. Ontogenetic course and spatial constraints in the appearance and disappearance of the terminal flower in inflorescences. Int J Plant Sci. 172: 471498. doi: $10.1086 / 658922$

Cao G-X, Kudo G. 2008. Size-dependent sex allocation in a monocarpic perennial herb, Cardiocrinum cordatum (Liliaceae). Pl Ecol. 194: 99-107. doi: 10.1007/s11258-007-9277-x

Claßen-Bockhoff R, Bull-Hereñu K. 2013. Towards an ontogenetic understanding of inflorescence diversity. Ann Bot. 112: 1523-1542. doi: 10.1093/aob/mct009

Conti E, Rutschmann F. 2004. Is the rare Saxifraga florulenta Moretti a Tertiary relictual species? Evidence from molecular dating analysis. Botanical Society of America meeting. Snowbird, UT, USA.

Conti E, Soltis DE, Hardig TM, Schneider J. 1999. Phylogenetic relationships of the silver saxifrages (Saxifraga, sect. Ligulatae Haworth): implications for the evolution of substrate specificity, life histories, and biogeography. Molec Phylog Evol. 13: 536-555. doi: 10.1006/mpev.1999.0673

Cruden RW. 1977. Pollen-ovule ratios: a conservative indicator of breeding systems in flowering plants. Evolution. 31: 32-46. doi: 10.1111/j.1558-5646.1977.tb00979.x

Cunningham SA. 2000. Depressed pollination in habitat fragments causes low fruit set. Proc R Soc Lond B. 267: 1149-1152. doi: 10.1098/rspb.2000.1121

De Jong TJ, Klinkhamer PGL. 1989. Size-dependency of sex-allocation in hermaphroditic, monocarpic plants. Funct Ecol. 3: 201-206. doi: 10.2307/2389301

De Jong TJ, Klinkhamer PGL. 1994. Plant size and reproductive success through female and male function. J Ecol. 82: 399-402. doi: 10.2307/2261307

Delesalle VA, Mazer SJ, Paz H. 2008. Temporal variation in the pollen:ovule ratios of Clarkia (Onagraceae) taxa with contrasting mating systems: field populations. J Evol Biol. 21: 310-323. 10.1111/j.1420-9101.2007.01444.x

Deng J, Drew BT, Mavrodiev EV, Gitzendanner MA, Soltis PS, Soltis DE. 2015. Phylogeny, divergence times, and historical biogeography of the angiosperm family Saxifragaceae. Mol Phylogenet Evol. 83: 86-98. doi: 10.1016/j.ympev.2014.11.011

Diggle PK. 1997. Extreme preformation in alpine Polygonum viviparum: an architectural and developmental analysis. Am J Bot. 84(2): 154-169. doi: 10.2307/2446077

Dinnétz P, Nilsson T. 2002. Population viability analysis of Saxifraga cotyledon, a perennial plant with semelparous rosettes. Pl Ecol. 159: 61-71. doi: 10.1023/A:1015593311183

Ebersbach J, Muellner-Riehl AN, Michalak I, Tkach N, Hoffmann MH, Röser M, Sun H, Favre A. 2017. In and out of the Qinghai-Tibet Plateau: divergence time estimation and historical biogeography of the large arctic-alpine genus Saxifraga L. J. Biogeogr. 44: 900-910. doi: $10.1111 /$ jbi.12899 
Elberling H, Olesen JM. 1999. The structure of a high latitude plant-flower visitor system: the dominance of flies. Ecography. 22: 314-323. doi: 10.1111/j.1600-0587.1999.tb00507.x

Fabbro T, Korner C. 2004. Altitudinal differences in flower traits and reproductive allocation. Flora. 199(1): 70-81. doi: 10.1078/0367-2530-00128

Focquet P, Romain J. 1988. La Saxifrage florulente. Une plante, un symbole, une légende. Rivièra Sci. 10: 25-39. French.

Fulkerson JR, Whittall JB, Carlson ML. 2012. Reproductive ecology e severe pollen limitation in the polychromic tundra plant, Parrya nudicaulis (Brassicaceae). PLoSONE. 7: e32790. doi: 10.1371/journal.pone.0032790

Gao J, Xiong YZ, Huang SQ. 2015. Effects of floral sexual investment and dichogamy on floral longevity. Plant Ecol. 8(2): 116-121. doi: 10.1093/jpe/rtv011

Garcia MB. 2003. Sex allocation in a long-lived monocarpic plant. Plant Biol. 5: 203-209. doi: $10.1055 / \mathrm{s}-2003-40728$

Goodwillie C, Weber JJ. 2018. The best of both worlds? A review of delayed selfing in flowering plants. Am J Bot. 105: 641-655. doi: 10.1002/ajb2.1045

Grey-Wilson C. 1985. Plants in peril, Saxifraga florulenta. Kew Mag 2: 232-234.

Guerrina M, Casazza G, Conti E, Macrì C, Minuto L. 2016. Reproductive biology of an Alpic paleo-endemic in a changing climate. J Plant Res. 129:477-485. doi: 10.1007/s10265-0160796-1

Gugerli F. 1998. Effect of elevation on sexual reproduction in alpine populations of Saxifraga oppositifolia (Saxifragaceae). Oecologia. 114: 60-66. doi: 10.1007/s004420050420

Guitián J, Medrano M, Oti JE. 2004. Variation in floral sex allocation in Polygonatum odoratum (Liliaceae). Ann Bot 94(3): 433-440. doi: 10.1093/aob/mch163

Harrell FE jr with contributions from Charles Dupont and many others. 2017. Hmisc: Harrell miscellaneous. $\mathrm{R}$ package version 4.0-3. https://CRAN.R-project.org/package $=$ Hmisc

Holderegger R. 1996. Reproduction of the rare monocarpic species Saxifraga mutata L. Bot J Linn Soc. 122: 302-313. doi: 10.1111/j.1095-8339.1996.tb02078.x

Ishii HS, Harder LD. 2012. Phenological associations of within- and among-plant variation in gender with floral morphology and integration in protandrous Delphinium glaucum. J Ecol. 100(4): 1029-1038. doi: 10.1111/j.1365-2745.2012.01976.x

Ishii HS, Sakai S. 2002. Temporal variation in floral display size and individual floral sex allocation in racemes of Narthecium asiaticum (Liliaceae). Am J Bot. 89: 441-446. doi: 10.3732/ajb.89.3.441

Juillet N, Zappa E 2011. Saxifraga florulenta. The IUCN Red List of Threatened Species 2011: e.T162137A5547943. doi: 10.2305/IUCN.UK.2011-1.RLTS.T162137A5547943.en. Down loaded on 04 March 2020. 
Klinkhamer PGL, De Jong TJ. 1997. Size-dependent allocation to male and female reproduction. In Bazzaz FA, Grace J, editors. Plant resource allocation. Academic Press, London, UK; pp 211230.

Klinkhamer PGL, De Jong TJ, Metz H. 1997. Sex and size in cosexual plants. Trends Ecol Evol. 12(7): 260-265. doi: 10.1016/S0169-5347(97)01078-1

Knight TM, Steets JA, Vamosi JC, Mazer SJ, Burd M, Campbell DR, Dudash MR, Johnston MO, Mitchell RJ, Ashman T-L. 2005. Pollen limitation of plant reproduction: pattern and process. Annu Rev Ecol Evol S. 36: 467-497. doi: 10.1146/annurev.ecolsys.36.102403. 115320

Körner C. 1999. Alpine plant life: Functional plant ecology of high mountain ecosystems. New York: Springer.

Kudo G. 1991. Effects of snow-free period on the phenology of alpine plants inhabiting snow patches. Arct Alp Res. 23: 436-443. doi: 10.1080/00040851.1991.12002863

Levin DA. 2012. Mating system shifts on the trailing edge. Ann Bot. 109: 613-620. doi: $10.1093 / \mathrm{aob} / \mathrm{mcr} 159$

Lindgaard-Hansen JE, Molau U. 1994. Pollination biology, mating system and seed set in a Danish population of Saxifraga granulata. Nord J Bot. 14: 257-268. doi: 10.1111/j.17561051.1994.tb00597.x

Lloyd DG. 1992. Self- and cross-fertilization in plants. II. The selection of self-fertilization. Int J Plant Sci. 153: 370-380. doi: 10.1086/297041

Lloyd DG, Schoen DJ. 1992. Self- and cross-fertilization in plants. I. Functional dimensions. Int J Plant Sci. 153: 358-369. doi: 10.1086/297040

Lloyd G, Webb CJ. 1986. The avoidance of interference between the presentation of pollen and stigmas in Angiosperms. I. Dichogamy. New Zeal J Bot. 24: 135-162. doi: 10.1080/0028825X.1986.10409725

Martini E. 1982. Lineamenti geobotanici delle Alpi Liguri e Marittime: endemismi e fitocenosi. Biogeographia. 9(1): 51-134. Italian. doi: 10.21426/B69110122

Mazer SJ, Dawson KA. 2001. Size-dependent sex allocation within flowers of the annual herb Clarkia unguiculata (Onagraceae): ontogenetic and among-plant variation. Am J Bot. 88: 819831. doi: $10.2307 / 2657034$

Medan D, Montaldo NH, Mantese A, Vasellati V, Roitman GG, Bartoloni NH. 2002. Plant-pollinator relationships at two altitudes in the Andes of Mendoza, Argentina. Arct Antarct Alp Res. 34: 233-241. doi: 10.1080/15230430.2002.12003490

Molau U. 1996. Climatic impacts on flowering, growth and vigour in an arctic-alpine cushion plant, Diapensia lapponica, under different snow cover regimes. Ecol Bull. 45: 210-219.

Molau U, Prentice HC. 1992. Reproductive system and population structure in three arctic Saxifraga species. J Ecol. 80: 149-161. doi: 10.2307/2261072 
Munné-Bosch S, Cotado A, Morales M, Fleta-Soriano E, Villellas J, Garcia MB. 2016. Adaptation of the long-lived monocarpic perennial Saxifraga longifolia to high altitude. Plant Physiol. 172: 765-775. doi: 10.1104/pp.16.00877

Muñoz AA, Arroyo MTK. 2006. Pollen limitation and spatial variation of reproductive success in the insect-pollinated shrub Chuquiraga oppositifolia (Asteraceae) in the Chilean Andes. Arct Antarct Alp Res. 38: 608-613. doi: 10.1657/1523-0430(2006)38[608:PLASVO] 2.0.CO;2

Narbona E, Dirzo R. 2010. A reassessment of the function of floral nectar in Croton suberosus (Euphorbiaceae): a reward for plant defenders and pollinators. Am J Bot. 97: 672-679.

Ohlson M. 1988. Size-dependent reproductive effort in three populations of Saxifraga hirculus in Sweden. J Ecol. 76: 1007-1016. doi: 10.3732/ajb.0900259

Olesen JM, Jordano P. 2002. Geographic patterns in plant-pollinator mutualistic networks. Ecology. 83: 2416-2424. doi: 10.1890/0012-9658(2002)083[2416\%3AGPIPPM]2.0.CO \%3B2

Olesen JM, Warncke E. 1989. Flowering and seasonal changes in flower sex ratio and frequency of flower visitors in a population of Saxifraga hirculus. Holarctic Ecol. 12: 21-30. doi; 10.1111/j.1600-0587.1989.tb00818.x

Patsiou TS, Conti E, Zimmermann NE, Theodoridis S, Randin CF. 2014. Topo-climatic microrefugia explain the persistence of a rare endemic plant in the Alps during the last 21 millennia. Global Change Biol. 20: 2286-2300. doi: 10.1111/gcb.12515

Pohlert T. 2014. The pairwise multiple comparison of mean ranks package (PMCMR). R package. pp.1-9. Available at: http://cran.r-project.org/package=PMCMR.

R Development Core Team. 2009. R: a language and environment for statistical computing. R Foundation for Statistical Computing, Vienna, Austria. http://www.r-project.org

Sletvold N. 2002. Effects of plant size on reproductive output and offspring performance in the facultative biennial Digitalis purpurea.J Ecol. 90(6): 958-966. doi: 10.1046/j.13652745.2002.00725.x

Soltis DE, Mort ME, Latvis M, Mavrodiev EV, O'Meara BC, Soltis PS, Burleigh JG Rubio de Casas R. 2013. Phylogenetic relationships and character evolution analysis of Saxifragales using a supermatrix approach. Am J Bot. 100: 916-929. doi: 10.3732/ajb.1300044

Stearns S. 1992. The evolution of life histories. Oxford University Press.

Stebbins GL. 1950. Variation and evolution in plants. New York, NY, USA: Columbia University Press.

Stebbins GL. 1957. Self fertilization and population variability in the higher plants. Am Nat. 91: 337-354. doi: 10.1086/281999

Steinacher G, Wagner J. 2010. Flower longevity and duration of pistil receptivity in high mountain plants. Flora. 205: 376-387. doi: 10.1016/j.flora.2009.12.012 
Stenström M, Molau U. 1992. Reproductive ecology of Saxifraga oppositifolia: phenology, mating system, and reproductive success. Arct Antarct Alp Res. 24: 337-343. doi:

10.1080/00040851.1992.12002966

Szövényi P, Arroyo K, Guggisberg A, Conti E. 2009. Effects of Pleistocene glaciations on the genetic structure of Saxifraga florulenta (Saxifragaceae), a rare endemic of the Maritime Alps. Taxon. 58: 532-543. doi: 10.1002/tax.582017

Thomann M, Imbert E, Devaux C, Cheptou P-O. 2013. Flowering plants under global pollinator decline. Trends Plant Sci. 18: 353-359. doi: 10.1016/j.tplants.2013.04.002

Tkach N, Röser M, Miehe G, Muellner-Riehl AN, Ebersbach J, Favre A, Hoffmann MH. 2015. Molecular phylogenetics, morphology and a revised classification of the complex genus Saxifraga (Saxifragaceae). Taxon. 64: 1159-1187. doi: 10.12705/646.4

Torres-Díaz C, Gómez-González S, Stotz GC, Torres-Morales P, Paredes B, Pérez-Millaqueo M, Gianoli E. 2011. Extremely long-lived stigmas allow extended cross-pollination opportunities in a high Andean plant. PLoS ONE. 6: e19497. doi: 10.1371/journal.pone.0019497

Vittoz P, Engler R. 2007. Seed dispersal distances: a typology based on dispersal modes and plant traits. Bot Helv. 117: 109-124. doi: 10.1007/s00035-007-0797-8

Webb DA, Gornall RJ. 1989. A manual of saxifrages and their cultivation. Portland, OR Timber Press.

Young TP, Augspurger CK. 1991. Ecology and evolution of long-lived semelparous plants. Trends Ecol Evol. 6: 285-289. doi: 10.1016/0169-5347(91)90006-J

Zhang Z. 2013. Phylogenetic studies in the genus Saxifraga (Saxifragaceae). University of Leicester. Thesis. https://hdl.handle.net/2381/28041. 
Table 1 - Floral and inflorescence phenology in Saxifraga florulenta. For each plant flowering individual $(n=15)$, the population of origin (Pop.) is indicated (LC = Lago del Chiotas; $R R=$ Rifugio Remondino). Basal rosette diameter ( $\varnothing$ ros) and height of the flowering scape (h scape) expressed in centimetres are reported for the 15 blooming plants of the study. For each inflorescence, terminal (T), first, second and third orders flowers are reported when present.

\begin{tabular}{|r|r|r|r|r|r|r|r|r|r|}
\hline & & \multicolumn{3}{|c|}{ Plants } & \multicolumn{5}{|c|}{ Flowers } \\
\hline Plant & Pop. & $\varnothing$ ros & $\mathrm{h}$ scape & $\mathrm{h} / \varnothing$ & $1^{\text {st }}$ order & $2^{\text {nd }}$ order & $3^{\text {rd }}$ order & $\mathrm{T}$ & TOT \\
\hline 1 & LC & 16.0 & 43.0 & 2.69 & 126 & 84 & 17 & 1 & 228 \\
\hline 2 & LC & 11.0 & 24.0 & 2.18 & 58 & 43 & 1 & 1 & 103 \\
\hline 3 & LC & 11.5 & 27.0 & 2.35 & 97 & 74 & 7 & 1 & 179 \\
\hline 4 & LC & 18.0 & 43.0 & 2.39 & 133 & 62 & 8 & 1 & 204 \\
\hline 5 & LC & 7.0 & 16.0 & 2.29 & 70 & 1 & 0 & 1 & 72 \\
\hline 6 & LC & 13.0 & 33.0 & 2.54 & 96 & 49 & 0 & 1 & 146 \\
\hline 7 & LC & 7.0 & 21.0 & 3.00 & 90 & 49 & 0 & 1 & 140 \\
\hline 8 & LC & 10.4 & 44.0 & 3.14 & 126 & 81 & 14 & 1 & 222 \\
\hline 9 & LC & 12.5 & 37.0 & 2.96 & 121 & 73 & 2 & na & 196 \\
\hline 10 & LC & 12.0 & 33.0 & 2.75 & 113 & 56 & 3 & 1 & 173 \\
\hline 11 & RR & 9.0 & 18.0 & 2.00 & 71 & 25 & 0 & 1 & 97 \\
\hline 12 & RR & 6.5 & 13.0 & 2.00 & 60 & 21 & 0 & 1 & 82 \\
\hline 13 & RR & 6.5 & 19.0 & 2.92 & 49 & 2 & 0 & 1 & 52 \\
\hline 14 & RR & 5.5 & 14.5 & 2.64 & 65 & 0 & 0 & 1 & 66 \\
\hline 15 & RR & 6.0 & 12.0 & 2.00 & 50 & 0 & 0 & 1 & 51 \\
\hline & Mean & 10.37 & 26.50 & 2.52 & 88.33 & 41.33 & 3.47 & 1.00 & 134.07 \\
\hline & SD & 3.93 & 11.52 & 0.39 & 29.96 & 31.05 & 5.55 & 0.00 & 63.34 \\
\hline
\end{tabular}


Table 2 - List of insects recorded visiting S. florulenta during the course of this study.

\begin{tabular}{|c|c|c|c|c|c|c|}
\hline Order & Suborder & Family & Subfamily & Genus & $\mathbf{N}$ & $\%$ \\
\hline \multirow[t]{2}{*}{ Hymenoptera } & & Apidae & & Bombus & 14 & \multirow{2}{*}{25.42} \\
\hline & & Apidae & & & 1 & \\
\hline \multirow[t]{5}{*}{ Diptera } & Nematocera & & & & 1 & \multirow{5}{*}{40.68} \\
\hline & & Empididae & & Hilara & 3 & \\
\hline & & Empididae & & & 5 & \\
\hline & Brachyera & Shyrphidae & & & 3 & \\
\hline & others & & & & 12 & \\
\hline \multirow[t]{3}{*}{ Coleoptera } & & Staphylinidae & Omalinae & & 3 & \multirow{3}{*}{11.86} \\
\hline & & Chrysomelidae & & & 2 & \\
\hline & Adephaga & & & & 2 & \\
\hline \multirow[t]{2}{*}{ Thysanoptera } & & Thripidae & & & 4 & \multirow{2}{*}{10.17} \\
\hline & & Aelothripidae & & & 2 & \\
\hline Lepidoptera & & Yponomeutidae & & Kessleria & 7 & 11.86 \\
\hline
\end{tabular}


Table 3 - Mean fruit production and mean fruit set in open-pollinated Saxifraga florulenta. Data are reported for the whole inflorescence and its three sections ( $B=$ basal; $M=$ median; $A=$ apical; $T=$ terminal).

\begin{tabular}{|c|r|r|r|r|r|r|r|r|r|r|r|r|r|r|r|}
\hline & \multicolumn{4}{|c|}{ Flowers } & \multicolumn{4}{|c|}{ Fruits } & \multicolumn{4}{|c|}{ Fruit set } \\
\hline & B & $\mathrm{M}$ & $\mathrm{A}$ & $\mathrm{T}$ & TOT & $\mathrm{B}$ & $\mathrm{M}$ & $\mathrm{A}$ & $\mathrm{T}$ & $\mathrm{TOT}$ & $\mathrm{B}$ & $\mathrm{M}$ & $\mathrm{A}$ & $\mathrm{T}$ & $\mathrm{TOT}$ \\
\hline Mean & 40.47 & 29.60 & 18.27 & 1.00 & 89.33 & 40.47 & 29.60 & 17.00 & 0.67 & 87.73 & 1.00 & 1.00 & 0.91 & 0.67 & $\mathbf{0 . 9 8}$ \\
\hline SD & 13.18 & 10.06 & 7.52 & 0.00 & 29.96 & 13.18 & 10.06 & 8.24 & 0.49 & 30.30 & 0.00 & 0.00 & 0.17 & 0.49 & 0.03 \\
\hline
\end{tabular}


Table 4 - Relative mean ovule and seed productions in open-pollinated flowers of Saxifraga florulenta. Data are reported for the whole inflorescence and its three sections ( $B=$ basal; $M=$ median; $A=$ apical; $T=$ terminal).

\begin{tabular}{|c|r|r|r|r|r|r|r|r|r|r|r|r|r|r|r|}
\hline & \multicolumn{4}{|c|}{ Ovules } & \multicolumn{4}{|c|}{ Seeds } & \multicolumn{4}{|c|}{ Seed set } \\
\hline & B & M & A & T & TOT & B & M & A & T & TOT & B & M & A & T & TOT \\
\hline Mean & 654.07 & 562.00 & 393.47 & 667.50 & 2054.53 & 460.33 & 418.47 & 290.67 & 519.10 & 1515.53 & 0.75 & 0.77 & 0.76 & 0.79 & $\mathbf{0 . 7 6}$ \\
\hline SD & 236.97 & 248.08 & 142.90 & 239.83 & 771.84 & 134.23 & 161.23 & 106.54 & 158.60 & 425.12 & 0.17 & 0.13 & 0.16 & 0.11 & 0.10 \\
\hline
\end{tabular}


Table 5 - Pearson and Kendall Tau correlations calculated in order to determine the relationships between plant size and reproductive investment variables in Saxifraga florulenta.

\begin{tabular}{|l|l|l|}
\hline & Kendall Tau & $\mathrm{p}$ value \\
\hline Rosette $\varnothing$ vs inflor. height & 0.8252427 & $2.369 \mathrm{e}^{-05}$ \\
\hline Rosette $\varnothing$ vs seed $\mathrm{n}$ & 0.5339806 & 0.006236 \\
\hline Rosette $\varnothing$ vs flowers & 0.7788822 & $5.862 \mathrm{e}^{-05}$ \\
\hline Rosette $\varnothing$ vs seed set & -0.3203883 & 0.1008 \\
\hline
\end{tabular}


Table 6 - Pollen and ovule production in Saxifraga florulenta. Pollen - ovule ratio (P:O) was calculated on a total of 24 flowers sampled in the three spatial sections of the inflorescence. Different letters indicate significant differences ( $p$ value threshold $=0.01$ ).

\begin{tabular}{|c|c|c|c|c|c|c|c|c|c|}
\hline Fl. position & \begin{tabular}{|l|} 
Pollen \\
\end{tabular} & SD & S. diff. & Ovule & SD & S. diff. & $\mathrm{P}: \mathrm{O}$ & SD & S. diff. \\
\hline Basal & 12500.00 & 4276.87 & $\mathrm{a}$ & 541.58 & 189.73 & $\mathrm{a}$ & 27.84 & 18.88 & $\mathrm{a}$ \\
\hline Median & 13244.05 & 5871.62 & $\mathrm{a}$ & 488.75 & 153.62 & $\mathrm{ab}$ & 29.78 & 16.14 & $\mathrm{a}$ \\
\hline Apical & 17098.71 & 4096.45 & $\mathrm{a}$ & 345.00 & 103.28 & $\mathrm{~b}$ & 52.58 & 16.51 & $\mathrm{~b}$ \\
\hline Terminal & 22791.67 & 11136.93 & I & 506.28 & 172.36 & 1 & 49.27 & 23.46 & I \\
\hline Mean & 16408.61 & 6345.47 & & 470.40 & 154.75 & & 39.87 & 18.75 & \\
\hline
\end{tabular}




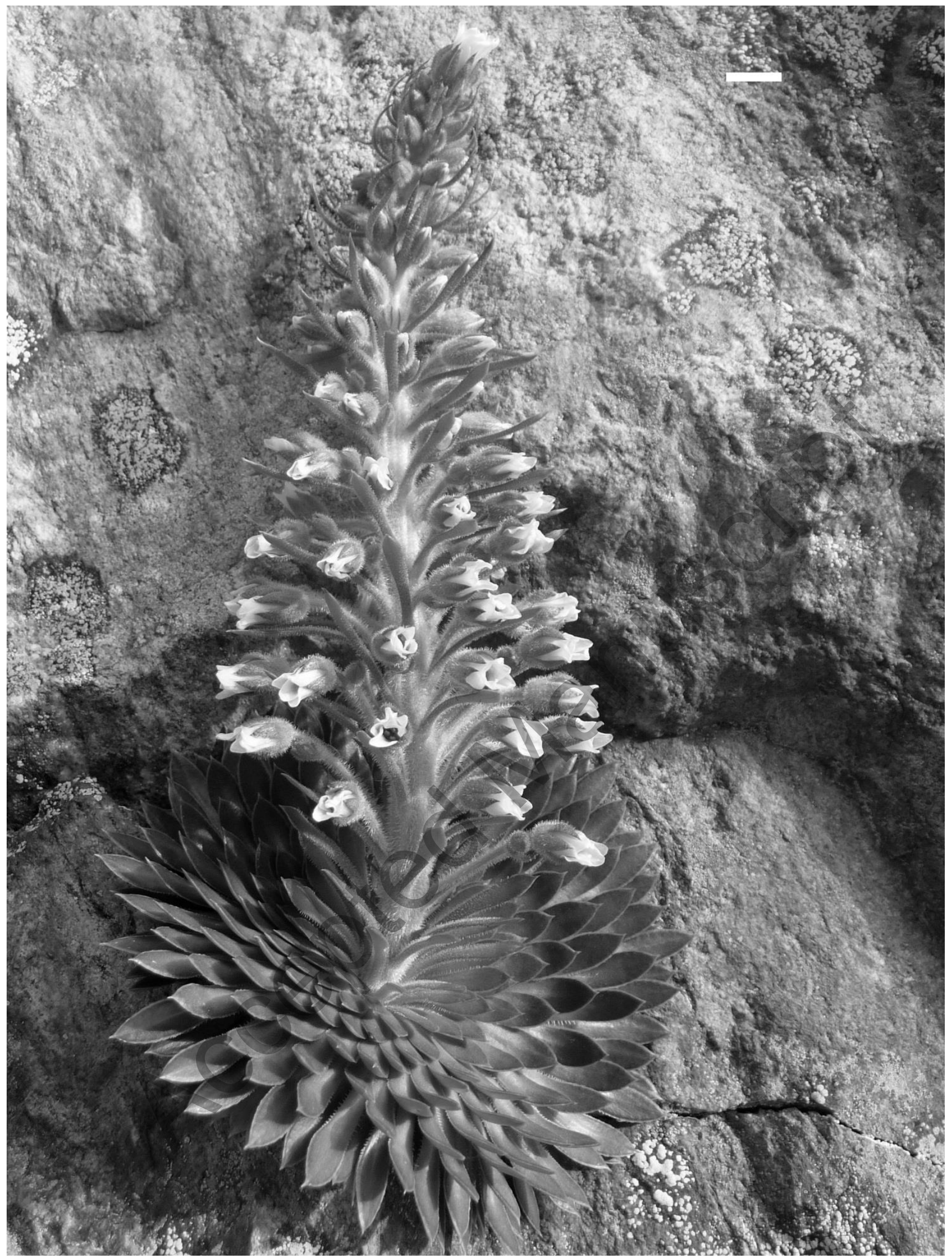

Fig 1 - Saxifraga florulenta in its natural habitat. The inflorescence blooms first with the terminal flower and later produces acropetally blooming waves. Bar $=2 \mathrm{~cm}$. 

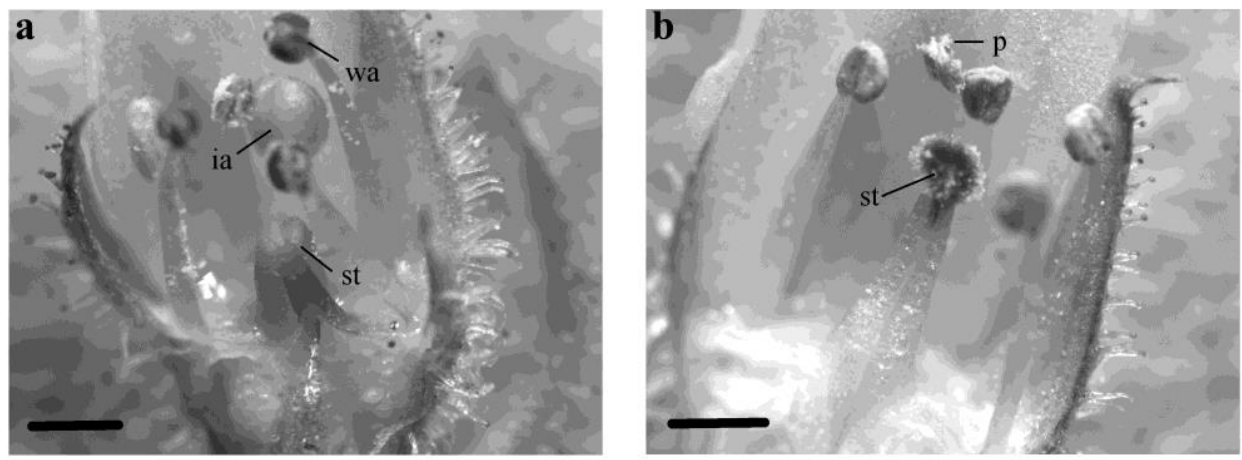

Fig 2 - Saxifraga florulenta flowers in bloom. a) Asynchronous maturation of stamens with half of the anthers (immature anthers $=i a$; wither anthers $=w a)$ dehiscent while the stigma (st) is not yet receptive. b) Senescent flowers with stamens collapsing toward the centre of the flower pushing their anthers with pollen ( $p$ ) on the still receptive stigma. Bar $=2 \mathrm{~mm}$. 


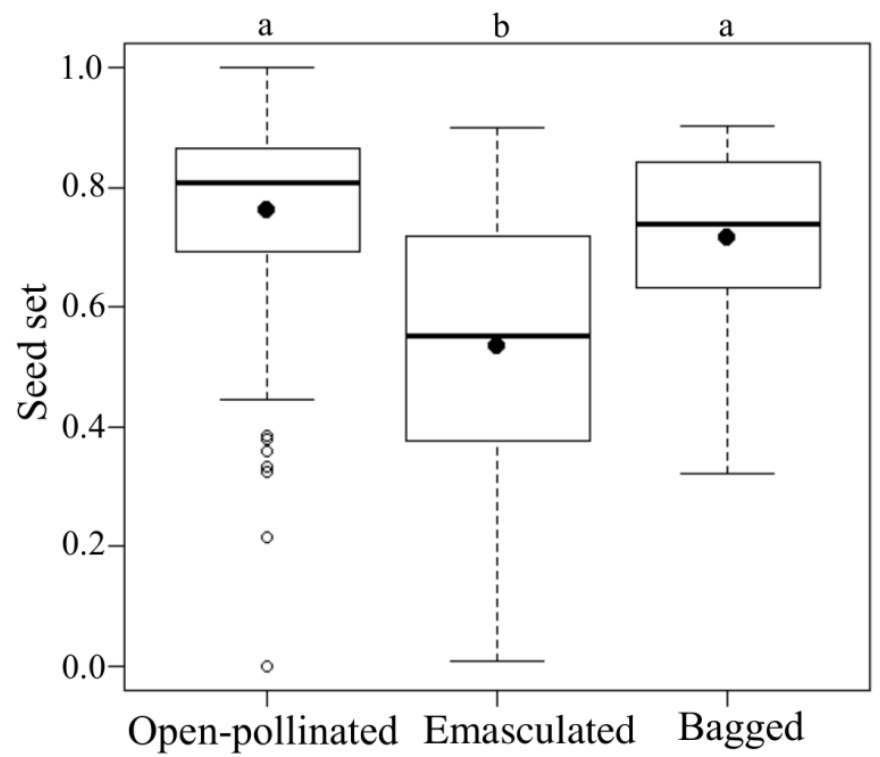

Fig 3 - Seed set in open-pollinated, emasculated and bagged flowers of Saxifraga florulenta. Results of post-hoc tests for statistical differences are reported: different letters indicate significant differences $(P<0.05)$. 